\title{
Echocardiographic identification of aorta and main pulmonary artery in complete transposition
}

Sir,

A. B. Houston et al. (British Heart fournal, 40, 377-382) describe the echocardiographic identification of aorta and main pulmonary artery in complete transposition with beautiful pictures.

It is easy to identify the aorta in transposition if you can recognise the brachiocephalic trunk arising from the anterior vessel. This is particularly so in the more complex anomalies such as transposition with pulmonary atresia. Strangely enough, Houston does not mention this sign though his Fig. 4 (page 379) is a beautiful example.

O. Daniëls,

Dept. of Paediatric Cardiology,

Universiteitsklinik voor Kindergeneeskunde, Nijmegen,

Holland.
This letter was shown to Dr Houston and his co-authors who reply as follows:

Sir,

We agree with Dr Daniëls, but since we have not always been able to visualise the brachiocephalic trunk (innominate artery) we have been unwilling to put this forward as a feature on which we may depend when identifying the aorta.
A. B. Houston,
N. L. Gregory, and E. N. Coleman,
Royal Hospital for Sick Children, Yorkhill, Glasgow G3 8SJ.

\section{Erratum}

Volume 40 (1978) pages 1306-1309: the authors have asked us to point out an error in their paper on 'Incidence of thyroid disease in cases of hypertrophic cardiomyopathy'. On page 1308, line 13 of the Discussion, the word 'largely' was printed in error for 'large'. 